\title{
Os percalços da política externa norte-americana em direção à Ásia: uma análise realista neoclássica do Pivô para a Ásia no governo de Barack Obama (2009-2016)
}

\author{
The mishaps of US foreign policy towards Asia: a neoclassical realist analysis of Asia Pivot under Barack \\ Obama (2009-2016)
}

DOI: https://doi.org/10.22456/2178-8839.101607

Alana Camoça Gonçalves de Oliveira Escola de Comando e Estado-Maior do Exército, Rio de Janeiro, Brasil alanacamoca@gmail.com

\section{Resumo}

O presente artigo tem como objetivo analisar a política do Pivô para a Ásia durante o governo de Barack Obama (2008-2016) por meio do Realismo Neoclássico. Nesse sentido, o presente artigo analisa as percepções das lideranças com relação às ameaças ou oportunidades no Leste Asiático, bem como as pressões domésticas que influenciaram a construção, a implementação e a condução do pivô durante o governo Obama. O artigo também analisa como a política do pivô afetou a percepção de países do Leste Asiático em relação ao comprometimento norte-americano com a região. Do ponto de vista metodológico, o artigo segue o método qualitativo, baseando-se em fontes primárias e secundárias para embasar os argumentos da pesquisa. $\mathrm{O}$ artigo conclui que os problemas orçamentários nos EUA, a ascensão de lideranças discursivamente contrárias aos custos das ações de segurança dos EUA em outros países, bem como pontos relacionados com a balança de poder interna norte-americana, afetaram negativamente a política do pivô. Ao passo que tal política se desenvolveu, as dúvidas sobre se os EUA continuariam, teriam capacidade de e agiriam no Leste Asiático impactaram as percepções dos países na região, impulsionando processos de militarização e dilemas de segurança no tabuleiro asiático.

Palavras-chave: Pivô para a Ásia; Realismo Neoclássico; EUA; Segurança Internacional;

\begin{abstract}
The objective of this article is to analyse the "Asia Pivot" US policy during Barack Obama's government (2008-2016) through the lenses of Neoclassical Realism. With that in mind, this article analyses the leadership perceptions regarding threats and opportunities in East Asia, as well as domestic pressures that influenced the development, implementation and actions of the policy during the Obama administration. The article also analyses how the Asia Pivot policy affected the East Asian countries' perception regarding US commitment with the region. From the methodology point of view, the article follows a qualitative approach, based in primary and secondary sources as the base of the research arguments. The article concludes that US budget problems, the rise of new leaderships against US expenditure and security actions in other countries, as well as issues involving the US internal power balance, affected in a negative way the Pivot policy. As the policy developed, doubts regarding US willingness and capacity to act in East Asia affected the perception of countries in the region, fuelling militarization processes and security dilemmas in the Asian theater.
\end{abstract}

Keywords: Pivot to Asia; Neoclassical Realism; USA; International Security; 


\section{Introdução}

"In the Asia Pacific in the 21st century, the United States of America is all in" afirmou o ex-presidente norte-americano Barack Obama (2009-2016) no dia 17 de novembro de 2011 em um discurso para o parlamento australiano. Tal discurso enfatizava sobre um redirecionamento da política externa dos EUA, ou ao menos um interesse por parte do governo norteamericano de agir de forma mais ativa na região do Ásia-Pacífico. Nos últimos anos, a Ásia se tornou um pólo dinâmico da economia mundial e um dos epicentros de tensionamentos e conflitos territoriais que vêm ocorrendo no Mar do Sul e no Mar do Leste da China. Diante desse cenário, novos/velhos dilemas de segurança passaram a influenciar as relações entre os países, o que impactou para que os EUA redimensionassem a sua política externa para a região. Tal política externa foi rotulada como "Pivô para a Ásia” ou "strategic rebalance”.

Em resumo, a reorientação estratégica deveria ser implementada por meio do fortalecim ento de relações bilaterais com países aliados, inicialmente, com o interesse na construção de um relacionamento construtivo com a China, e por meio da cooperação multilateral. Quando falamos sobre tal política, não existe unanimidade entre os especialista s sobre a sua efetividade e sobre os seus efeitos positivos e/ou negativos (HAROLD, 2015; ROSS, 2012; FORD, 2017; KOLMAS; KOLMASOVA, 2019). De fato, as consequências das ações do pivô não são compreendidas da mesma forma nem mesmo entre especialistas e lideranças de nações asiáticas e nações europeias. Nas palavras de Green (2017, p.522, tradução nossa), "na Europa, oficiais temiam que o pivô fosse real, enquanto, na Ásia, eles estavam preocupados que nãofosse”.

Além disso, questões sobre a efetividade, os efeitos e a durabilidade da política externa de Obama vem sendo tensionadas após a ascensão de Donald Trump ao poder em 2017. O atual presidente norte -americano desde a sua campanha presidencial de 2016 entoa discursos e blefes isolacionistas criticando o peso/custo das alianças para os EUA. Todavia, ao passo que tais discursos continuam, observa-se que o governo de Donald Trump tem também fortalecido suas relações com países da Ásia, sendo um exemplo a assinatura do The Asia Reassurance Initiative Act (Aria) em dezembro de 2018. Algumas iniciativas de Donald Trump que visam o fortalecimento de relações com países da região, bem como os interesses norte-americanos no Mar do Sul da China evocam sobre a continuidade ou até um fortalecimento da política externa dos EUA para Ásia durante o governo de Trump - exemplo, Free and Open Indo-Pacific Strategy (LIND, 2018; SLOAN, 2018).

As interpretações antagônicas sobre a política externa norte-americana para a Ásia em si e suas consequências fazem necessário um esforço de análise que retome às origens da formulação da política do Ásia Pivô. É necessário analisarmos os interesses, os objetivos e as visões que estavam em jogo no momento de tomada de decisão, na formulação e na implementação da política externa dos EUA no governo Obama. Somente a partir de tal ponto é possível traçar uma evolução sobre a política norte -americana para o tabuleiro asiático. Dessa maneira, o principal objetivo do presente artigo é recuperar o debate sobre a política externa dos EUA para a Ásia, analisando a política do pivô por meio da teoria realista neoclássica, com o intuito de compreender as ações tomadas e quais os efeitos dessas ações para o Ásia -Pacífico.

O artigo parte da seguinte pergunta de pesquisa: Quais os fatores (sistêmicos e domésticos) que influenciaram na condução e no desenvolvimento da política externa do pivô para a Ásia no governo de Barack Obama? O artigo parte da hipótese que apesar da política do pivô ser influenciada pela pressão sistêmica relacionada a o dinamismo e à ascensão da China, seus pressupostos, a forma que foi conduzida e a implementação da política foram também influenciadas por fatores domésticos. Os fatores domésticos, ou variáveis intervenientes, consideradas para o presente artigo são (i) as percepções de ameaça e oportunidades por parte das lideranças e das elites e (ii) a percepção por parte das lideranças e das elites em relação à capacidade de extração de recursos (a potência do estado em relação à sociedade).

Postula-se que tais influências impactaram na política, fazendo com que ela fosse descoordenada e duvidosa aos olhos de alguns países asiáticos. E consequentemente, a política de balanceamento gerou mais incertezas e intensificou dilemas de segurança na região. Para a condução da pesquisa, o artigo emprega uma metodologia qualitativa e analítica, alicerçada no uso de fontes primárias (Livros Brancos, documentos oficiais, discursos oficiais e etc.) e secundárias (artigos, 
livros, notícias e outras produções bibliográficas acerca do tema). $\mathrm{O}$ artigo se divide em quatro partes para além da introdução e da conclusão. Primeiramente, o artigo apresenta o marco teórico que guia as análises sobre a política do Pivô para a Ásia. Em segundo lugar, o artigo apresenta o contexto do Leste Asiático no século XXI, com ênfase na ascensão da China e em suas relações com os EUA. Em terceirolugar, o artigo debate sobre a política do Pivô, onde são feitas análises à luz do realismoneoclássico sobre sua formulação, implementação e efeitos. Por fim, o artigo debate sobre como os países da Ásia perceberam a política dos EUA e seus impactos na segurança regional.

\section{Realismo Neoclássico como ferramenta de análise de política externa}

O realismo neoclássico foi pela primeira vez introduzido no debate acadêmico pelo artigo de Gideon Rose "Neoclassical Realism and Theories of Foreign Policy" publicado na revista World Politics em 1998. Gideon Rose (1998) identificou um programa comum de pesquisa entre alguns estudos de realistas publicados na década de 1990, onde conjuminaram concepções do neorrealismo sobre a estrutura e a distribuição de poder no Sistema Internacional, da terceira imagem, com questões próximas do realismo clássico sobre variáveis da primeira e da segunda imagem das RIs (WALTZ,1959) para analis ar as políticas externas dos Estados no Sistema Internacional.

As análises neoclássicas, assim como as neorrealistas, partem da posição de um país no Sistema Internacional e, em particular, das suas capacidades relativas de poder material que constituem o parâmetro de seu próprio comportamento em nível internacional. Todavia, neoclássicos argumentam que raramente apenas os imperativos sistêmicos (variável independente) são as únicas forças que influenciam as ações dos países e seus tomadores de decisão. Afinal, as decisões estratégicas e a política externa dos Estados são feitas no nível doméstico por indivíduos que possuem crenças, personalidades, percepções e identidades, e que, ao mesmo tempo, sofrem com constrangimentos domésticos relacionados à própria estrutura do Estado. Isso faz necessário a criação de uma teoria multinível.

Logo, os realistas neoclássicos partem do princípio de que as condições estruturais são "causas permissivas ou 'profundas' de ações específicas: elas permitem que certas coisas aconteçam fornecendo oportunidades e restrições aos comportamentos dos atores” (Schweller, 1998, p.3, tradução nossa), o que possibilita a incorporação de variáveis de nível doméstico (variáveis intervenientes), para explicar o comportamento dos países e as suas políticas externas (variáveis dependentes) (ZAKARIA, 1998; CHRISTENSEN, 1996; ROSE, 1998).

Entretanto, enquanto existe certa homogeneidade entre os realistas neoclássicos que seguemos pressupostos do neorrealismo em que as variáveis sistêmicas são, principalmente, a polaridade e a distribuição de poder, as variáveis intervenientes são heterogêneas na literatura (RIPSMAN; LOBELL; TALIAFERRO, 2016). Para o presente artigo, as variáveis intervenientes consideradas são espelhadas na proposta de variáveis de Ilai Saltzman (2015) e, em parte, também mobilizadas por Ripsman, Taliaferro e Lobell (2016) e Christensen (1996) em suas categorizações. Nesse sentido, o artigo compreende como variáveis intervenientes (i) as percepções de ameaça e oportunidades por parte das lideranças e das elites e (ii) a percepção por parte das liderançase das elites em relação à capacidade de extração de recursos (a potência do Estado em relaçãoà sociedade).

No que tange à primeira, como argumenta Wohlforth (1993), se o poder influencia as relações internacionais, ele o faz por meio das percepções daqueles que agem em nome do Estado. Para o presente artigo, os indivíduos e as lideranças desse processo de decisão incluem o presidente ou primeiro-ministro, assim como os membros do gabinete, membros da alta burocracia (Inteligência, Departamento de Estado/Defesa), ministros e conselheiros. Como apontam Ripsman, Taliaferro e Lobell (2016), tais lideranças detêm informações privilegiadas sobre o sistema internacional para decidir como agir em relação aos constrangimentos, às ameaças e às oportunidades.

Todavia, em diversos momentos, para os países conseguirem promover mudanças em suas políticas ou ajustá-las é necessário o apoio da população. Como argumenta Saltzman (2015), a disponibilidade de recursos materiais nãogarante 
que os governos tenham a capacidade de convertê-los em poder. Nesse sentido, a balança de poder interna influencia a formulação das políticas, sobretudo se considerarmos democracias que são mais vulneráveis aos problemas de legitimidade no que tange à opinião pública (SALTZMAN, 2015). Como argumenta Christensen (1996, p.11, tradução nossa) “sem um grau saudável de consenso por trás das estratégias de segurança, nenhum Estado pode aproveitar sua população e projetar o poder nacional no exterior”.

No caso dos EUA, objeto de análise do artigo, o sistema norte -americano de “checks and balances” em relação ao Executivo e ao Congresso dificulta a ação de algumas decisões de lideranças norte -americanas em momentos que estes necessitem modificar suas grandes estratégias e/ou redimensionar suas políticas externas, dada a influência do Congresso nos orçamentos do país ${ }^{1}$. O nível de coesão política e social dentro de um Estado e o apoio da opinião pública para a implementação de uma política externa e/ou o apoio aos objetivos nacionais de segurança são alguns dos fatores que podem afetar a capacidade das lideranças “de extrair, mobilizar e aproveitar o poder da nação” (RIPSMAN; TALIAFERRO; LOBELL, 2016, p.71, traduçãonossa).

\section{A Geopolítica do Ásia-Pacífico no século XXI: as dinâmicas de poder, a ascensão da China e os EUA}

Nas últimas décadas, a região do Leste Asiático atraiu a atenção de internacionalistas e especialistas econômicos, políticos e culturais devido ao fato da relevância que a região conquistou nos últimos anos. No séculoXXI os conflitos no teatro de segurança asiático estão sendo revisitados e novos/velhos dilemas de segurança vem sendo impulsionados em um contexto de rivalidades históricas. Do ponto de vista econômico, a dinamicidade do Leste Asiático que pode ser atribuída principalmente pelo crescimento econômico de países da região, sobretudo na década de 1990 e nos anos mais recentes com destaque ao crescente desenvolvimento chinês, está reorientando o eixo econômico mundial. A criação de instituições econômicas e financeiras, como o Banco de Desenvolvimento Asiático (AIIB), e os projetos de desenvolvimento infraestrutural na região, como exemplo da Belt and Road Initiative (BRI), são exemplos da centralidade da região na atual conjuntura.

Além disso, disputas territoriais vêm emergindo no séculoXXI, principalmente a partir de 2009, e escalonando a níveis alarmantes tanto no Mar do Sul, como no Mar do Leste da China. Para além das disputas territoriais, do ponto de vista político-estratégico, cabe ressaltar ainda:i) os continuados, apesar de oscilantes, tensionamentos relacionados com as ações da Coreia do Norte - seus blefes e testes militares -,ii) as transformações da política de segurança doJapão desde a era Koizumi (2001-2006) e de forma mais evidente durante o governo de Shinzo Abe (2012-2020), iii) a modernização das forças militares da China, bem como as instabilidades de movimentos nacionalistas em regiões dentro da China e iv) as próprias transformações políticas em Taiwan, na Coreia do Sul e nas Filipinas.

De fato, desde o final da Segunda Guerra Mundial o Leste Asiático foi uma região estratégica para os EUA. Logo no início da Guerra Fria, os conflitos na península coreana e os receios com relação à expansão do comunismo na Ásia impulsionaram sistemas de alianças dos EUA com países da região, como o caso dos tratados de segurança dos EUA com o Japão (1951 e modificado em 1960), Coreia doSul (1953) e Filipinas (1951). Nesse sentido, os EUA consolidaram sua presença no teatro de segurança do Leste Asiático por meio de suas alianças e da manutenção de tropas em territórios de países aliados. Apesar de algumas oscilações durante a Guerra Fria e no pós-Guerra Fria, esta presença continua a ser fundamental para a estratégia norte-americana ${ }^{2}$.

\footnotetext{
Apesar do poder do Congresso norte-americano, nota-se que, em diversos momentos da história, alguns presidentes dos EUA agiram sem solicitar autorização ao legislativo. Como exemplo, podemos citar as ações de Harry Truman sobre a Guerra da Coreia (1951-1953), Ronald Reagan e o bombardeio à Líbia (1986) e a invasão à Granada (1983), George H.W Bush e a invasão do Panamá (1989) e outras que foram tomadas por presidentes norte-americanos sem a solicitação da autorização ao legislativo.

2 Nota-se que durante o governo de Donald Trump afirmações constantes sobre os custos das alianças dos EUA com países do mundo todo têm sido entoadas pela liderança. As demandas dos EUA são semelhantes em diversos teatros de segurança, onde o país demanda que os aliados arquem com os custos da aliança tanto do ponto de vista econômico como político. Além disso, Trump argumenta constantemente sobre a necessidade de tornar as alianças mais simétricas, o que tem afetado o comportamento, por exemplo, do Japão. O arquipélago vem transformando suas políticas de segurança,
} 
Todavia, mesmo os EUA nunca tenham “saído" da região do Leste Asiático e que tal teatro de segurança tenha obtido ao longo dos anos notoriedade na agenda de política externa dos EUA, principalmente a partir do século XXI a política externa dos EUA concentrou esforços na região do Oriente Médio. Enquanto os EUA direcionaram seus esforços para as "guerras infinitas" no Oriente Médio, a Ásia foi vista como um espaço para promover relações estáveis com os países da região, inclusive com a China (ZHAO, 2015; CHRISTENSEN, 2015).

Cabe destacar o papel e a questão da China. Afinal, mesmo com a crise do Estreito de Taiwan em abril de 2001, os governos norte-americano e chinês buscaram construir relações amistosas - característica que pode ser explicada pelos próprios objetivos da política externa de Jiang Zemin e Hu Jintao (ZHAO, 2015). Segundo Christensen (2015), Bush optou por medidas conciliatórias com o gigante asiático, mesmo que restassem constantes dúvidas sobre se a China seria uma ameaça que requer contenção ou seria um país que precisava se engajar com a ordem internacional endossada pelos EUA.

Ao passo que se fortaleciam relações mais cooperativas entre os EUA e o Leste Asiático, o redimensionamento estratégico norte-americano para o Oriente Médio não trouxe efeitos positivos (GREEN, 2017).Em linhas gerais, a política externa do governo Bush trouxe consequências negativas para a economia norte-americana e para a legitimidade do país internacionalmente. Pontos estes que vão ser evidenciados nos governos posteriores. Inclusive, as críticas sobre a atuação dos EUA e as suas "guerras infinitas" e sem sentido são trazidas por autores como Mearsheimer (2019) e Walt (2019) para criticar a condução e os erros da estratégia de “crusader" e "overextension" que guiou a política externa do país no período.

A administração de Barack Obama (2009-2016) herdou os problemas financeiros da crise de 2008 e a criticada atuação norte-americana no Oriente Médio (Afeganistão e Iraque). Por esse motivo, perseguiu um caminho de desengajar os EUA desses conflitos.

Nos últimos 10 anos, alocamos recursos imensos para esses dois teatros [Afeganistão e Iraque]. Nos próximos 10 anos, precisamos ser inteligentes e sistemáticos sobre onde investimos tempo e energia, a fim de nos colocarmos na melhor posição para sustentar nossa liderança, proteger nossos interesses e promover nossos valores. Uma das tarefas mais importantes da política americana ao longo da próxima década será, portanto, garantir um investimento substancialmente maior - diplomático, econômico, estratégico e diverso - na região Ásia-Pacífico (CLINTON, 2011, tradução nossa).

Entretanto, o desengajamento de Obama não se consolidou por completo e no fim do seu mandato, críticas a respeito das decisões tomadas pela administração norte-americana ainda trazem consequências para os conflitos na região. No caso do Leste Asiático, a sua dinamicidade econômica, o contínuo crescimento chinês mesmo após a crise de 2008 e o reavivamento de disputas na região do Ásia-Pacífico concentradas, principalmente, no Mar do Sul e no Mar do Leste da China, foram (e continuam sendo) elementos decisivos no teatro de segurança do LesteAsiático.

\section{A Política do Pivô para a Ásia: uma breve apresentação}

Barack Obama assumiu o governo em 2009 herdando os legados das administrações anteriores, o que impactou na condução de sua política externa para o Leste Asiático. Inicialmente, a administração de Obama enfatizou discursivamente a diplomacia, o multilateralismo e o respeito à ordem internacional como pilares de sua política externa, visando distanciar-se do unilateralismo de Bush (PECEQUILO, 2010; BRANDS, 2017). De acordo com Brands (2017), Obama enfatizou a necessidade de injetar maior restrição, corte de custos e precisão no uso do poder militar dos EUA, de dobrar o compromisso diplomático com amigos e rivais e de "reequilibrar" a política americana geograficamente, à luz do surgimento da Ásia-Pacífico como o ponto central da geopolítica e da geoeconomia do séculoXXI.

sobretudo após a ascensão de Shinzo Abe em 2012 como primeiro-ministro e vem cedendo às pressões de Donald Trump. Nota-se que no caso da aliança entre EUA e Japão, tal comportamento onde os EUA demandam e o Japão cedem o suficiente para agradar as lideranças norte-americanas são constantes na história das relações entre os países no pós-Segunda Guerra Mundial (LIND, 2018). 
Em 2007, Obama escreveu um artigo à Foreign Affairs, intitulado “Renewing American Leadership”, onde propõe novos caminhos e faz menções sobre os desafios encontrados à política externa norte -americana. Em linhas gerais, podese argumentar que a política do pivô foi multidimensional, ou pelo menos tinha como objetivo ser, e se base ou, principalmente, em três princípios: (i) a economia, (ii) a segurança e (iii) a promoção da dignidade humana, sendo que o último deles foi logo esquecido pelos articuladores da política norte-americana. De acordo com o Relatório do Pentágono de 2012, intitulado “Sustaining US Global Leadership: Priority to 21st century Defense”, o governo norte-americano explicita a política de rebalance para o Ásia-Pacífico e afirma que:

\begin{abstract}
Enquanto os EUA continuarão a contribuir militarmente para a segurança global, nós precisaremos necessariamente balancear em direção à região da Ásia - Pacífico. Nossas relações com aliados asiáticos e parceiros-chave são fundamentais para a futura estabilidade e crescimento da região. Vamos enfatizar nossas alianças existentes, que fornecem uma base vital para a segurança da Ásia-Pacífico. Também expandiremos nossas redes de cooperação com parceiros emergentes em toda a Ásia-Pacífico para garantir a capacidade coletiva e a capacidade de garantir interesses comuns (US DEPARTMENT OF DEFENSE, 2012, p. 2, tradução nossa).
\end{abstract}

Economicamente, o governo dos EUA buscou manter a diversificação dos laços econômicos na região, ao mesmo tempo promovendo políticas para diminuir o poder gravitacional econômico da China - o que se relaciona com o Trans Pacific Partnership (TPP). Afinal, desde 2010 a China já havia ultrapassado o Japão como a segunda maior economia do mundo e a capilaridade do poder econômico chinês vem aumentando nos últimos anos, seja por estratégias de internacionalização das empresas chinesas, investimento estrangeiro direto em países da Ásia ou o aumento das relações da China com países do mundo todo, sobretudo da África e da América Latina (OLIVEIRA, 2019).

Do ponto de vista da segurança, a política do pivô se consolidou de forma militar como resposta aos sucessivos tensionamentos marítimos da região que envolviam a China e às crescentes ameaças norte -coreanas (GREEN, 2017).Logo, a política tinha como pontos o fortalecimento de alianças e o estabelecimento de uma arquitetura econômica favorável à maior inserção norte-americana na região - que fosse capaz de aumentar os benefícios do comércio e do crescimento (CORDESMAN; HESS, 2013). Além disso, a política do pivô tinha o interesse de fortalecer as instituições regionais, tanto que os EUA também visaram modificar a estrutura institucional já existentena Ásia por meio da sua entrada na Cúpula do Leste Asiático (EAS), por exemplo (BRANDS, 2017; GREEN, 2017).

De fato, as ações iniciais de Obama com relação à China também sintetizavam aspectos de sua política externa que, inicialmente, priorizava o multilateralismo e o fortalecimento de relações construtivas com outros países do sistema internacional. A equipe da política externa de Obama defendeu um relacionamento mais próximo com a China. Henry Kissinger pediu que o relacionamento EUA-China fosse "levado a um novo nível" e Zbigniew Brzezinski defendeu o desenvolvimento de um G-2, um grupo de dois formado pela China e os EUA que poderia enfrentar a crise financeira internacional, enfrentar a mudança climática, limitar a proliferação de armas de destruição em massa e talvez até ajudar na resolução de conflitos regionais (ECONOMY; SEAGAL, 2009).

A política do pivô para a Ásia correspondia inicialmente aos interesses dos EUA de promover relações amistosas e cooperativas entre os países do ponto de vista econômico. Contudo, a estratégia do pivô logo se consolidou em um empreendimento mais proeminente no campo militar e de segurança. No geral, os objetivos da administração de Obama eram "reconstruir laços com nossos aliados na Europa e na Ásia e fortalecer nossas parcerias em todas as Américas e na África” (OBAMA, 2007, traduçãonossa).

Considerando a política do pivô em um primeiro momento, exemplos da postura conciliatória norte-americana podem ser vistos em duas ações: quando Obama optou por não se encontrar com Dalai Lama-liderança espiritual do Tỉbet - e quando tardou em ratificar o acordo sobre a venda de armas para Taiwan (CHRISTENSEN, 2015; ZHAO, 2015; OLIVEIRA, 2019). Em 2009, a China e os EUA assinaram uma declaração conjunta afirmando que "os dois lados concordaram que respeitar os interesses centrais dos países era de extrema importância para garantir o progresso das relações EUA - China” 
(US-CHINA Joint Statement, 2009, traduçãonossa). Entretanto, já em 2010 a postura mais conciliatória e acomodativa em relação à China começou a se transformar, na medida em que Obama visitou Dalai Lama em 2010, a administração dos EUA aprovou a venda de um pacote de armas para Taiwan e os EUA passaram a atuar mais ativamente na região do Mar do Sul e do Leste da China.

As relações com os EUA se aprofundaram com os países do Sudeste Asiático. Ainda em 2010, Robert Gates, então secretário de Defesa, e Hillary Clinton, então Secretária de Estado, visitaram países no Sudeste Asiático com o objetivo de aprofundar as relações, como foi o caso da aproximação dos EUA com o Vietnã. Há também o fortalecimento de relações com antigos aliados, como a Coreia do Sul, quando os EUA reafirmam compromissos defensivos, e como o Japão, quando o governo norte-americano declarou que as ilhas Senkaku/Diaoyu - que são disputadas pela China,Japão e Taiwan - estão sob proteção da aliança nipo-americana (OLIVEIRA, 2019).

Entre 2010 e 2012, os EUA realizaram exercícios navais com o Vietnã e fortaleceram relações com os países do Sudeste Asiático, sobretudo, com as Filipinas antes do governo de Rodrigo Duterte, priorizando a alocação de oficiais militares na região (GREEN, 2017; OLIVEIRA, 2019). Desde 2015, o governo norte-americano já conduziu mais de cinco operações para a livre navegação dos mares (Freedom of Navigation Operations) (OLIVEIRA, 2019). Como parte da estratégia, postulava-se que, até 2020, grande parte da frota marítima norte-americana estaria no Pacífico. Isso seria possível por meio da consolidação das estratégias de penetração do poder militar norte -americano com acordos militares, como o caso entre EUA e Austrália - com a alocação de cerca de 2500 oficiais norte-americanos em Darwin (CORDEMAN; HESS, 2013; GREEN, 2017; CHRISTENSEN, 2015).

Desde a implementação da política do pivô para a Ásia houve um comportamento dual dos EUA em relação à China. Por um lado, o país norte-americano reconheceu a China como uma potência e realizou diversos diálogos estratégicos e econômicos com o gigante asiático com o objetivo de engajá-la com a ordem; e por outro, a administração norte-americana "mostrou disposição para agir onde o comportamento da China violava os interesses dos EUA, o que causou instabilidade regional, e também trabalhou com seus aliados para engajar e balancear o crescente poder chinês" (ZHAO, 2015, p.79, tradução nossa). A grande questão é que a política do pivô teve efeitos diferenciados na Ásia e foi percebida de forma diferenciada pelos países do LesteAsiático. Afinal, a própria política externa dos EUA para a Ásia esteve repleta de incongruências e discursos contrastantes, como apresentaremos na próxima seção.

Do ponto de vista chinês, a estratégia de pivô para a Ásia recebeu críticas de diversos oficiais, da mídia e de parcela da opinião pública chinesa, enquanto que, em outras partes da Ásia, ela foi bem -vinda. Nesse caso, cabe destacar uma pesquisa de opinião realizada pelo Center of Strategic International Studies (CSIS) (2014) sobre as percepções de especialistas acerca do pivô para a Ásia e a pesquisa do Pew Research Center (2015) que apresenta pesquisas sobre como algumas nações asiáticas compreendem os aspectos militares (defensivos) do pivô e as própria articulação doTPP.

No relatório de 2014 do CSIS, cerca de 77\% dos especialistas chineses desaprovavam a estratégia norte -americana do pivô, argumentando que esta seria muito confrontacional e pouco cooperativa. Entretanto, mais de $80 \%$ de especialistas de outros países da Ásia apoiavam as intenções de tal política (GREEN et al., 2014). Apesar do apoio, grande parte dos especialistas de outras nações asiáticas duvidavam sobre os recursos e tinham receios sobre a própria forma como a política vinha sendo implementada, diante dos constrangimentos orçamentários norte-americanos e das ações dos EUA em outros teatros de segurança ${ }^{3}$.

A pesquisa de opinião conduzida pelo Pew Research Center de 2015 também apresentou resultados semelhantes. De acordo com a pesquisa, quando questionados se a política dos EUA de direcionar/enviar mais recursos militares para a Ásia seria algo bom porque ajudaria a manter a paz na região ou seria negativo, tendo em vista que poderia levar a um conflito com a China, mais da metade dos entrevistados no Vietnã (71\%), nas Filipinas (71\%), no Japão (58\%), na Índia

\footnotetext{
3 As falhas e custosas ações dos EUA no Oriente Médio, a crise da Ucrânia e a anexação da região da Crimeia pela Rússia, por exemplo, impactaram a imagem e o prestígio dos EUA internacionalmente, assim como geraram dúvidas sobre o seu comprometimento internacional
} 
(55\%) e em outros países afirmaram que o compromisso dos EUA com a região seria benéfico para a promoção da estabilidade e manutenção da paz. Somente na Malásia a maior parte dos entrevistados (54\%) compreendiam que a política do pivô era confrontacional e poderia instigar disputas e tensões na região. Separadamente, também foram conduzidas perguntas para cidadãos chineses sobre se os EUA aceitariam o aumento de poder chinês ou se estavam tentando prevenir para que a China se tornasse tão poderosa quanto os EUA. Nesse caso, $54 \%$ dos entrevistados compreendiam que os EUA estavam tentando prevenir o aumento de poder do gigante asiático. No que diz respeito às iniciativas norte-americanas do ponto de vista econômico, das nações entrevistadas (Vietnã, Peru, Chile, México, Japão, Austrália, Canadá, EUA e Malásia), todas compreendiam que seria algo principalmente benéfico (PEW RESEARCH CENTER, 2015).

\section{Uma análise realista neoclássica do Pivô para a Ásia}

A estratégia de rebalance do governo norte-americano continua moldando as dinâmicas regionais doÁsia-Pacífico e esse não é um processo estático, mas evolutivo, que enfrentou e ainda enfrenta problemas. Compreender o pivô, a sua continuidade e os seus problemas é algo que podemos acessar com uma análise realista neoclássica que envolve não só questões no nível sistêmico, como também variáveis intervenientes relacionadas às percepções de ameaça e de oportunidade e à capacidade de mobilização de recursos.

Como toda a análise realista neoclássica é preciso considerarmos inicialmente as pressões sistêmicas, levando em consideração a distribuição de poder e a polaridade do sistema. Como argumentam Brooks e Wohlforth (2016), os EUA continuam sendo a principal potência do sistema internacional, apesar dos problemas econômicos que vivenciaram com a crise de 2008 e em face a ascensão da China como grande potência. Dessa maneira, nas palavras dos autores, "a ascensão da China ao potencial emergente do nível de superpotência não altera essa realidade estrutural” e, portanto, o sistema internacional continua, mesmo com transformações no poder relativo e o crescimento chinês, unipolar (BROOKS; WOHLFORTH, 2016, tradução nossa).

Todavia, afirmar sobre a continuidade da unipolaridade ainda durante a administração Obama não significa dizer que deixaram de ocorrer transformações na balança de poder entre os países, sobretudo quando consideramos o nível regional, a continuidade dos investimentos chineses na modernização de suas forças militares ${ }^{4}$ e seu crescimento econômico internacionalmente - por meio da ampliação de parcerias com países do Sul Global, dos investimentos em inovação, da criação de instituições financeiras e de seus projetos infraestruturais como a BRI (ZHAO, 2015; NOGUEIRA; HENDLER, 2016).

De acordo com dados do Banco Mundial (2020), em 2010 a China superou o Japão como a segunda maior economia do mundo em termos nominais. Desde então, permaneceunessa posição, diminuindo progressivamente o hiato em relação aos EUA. Todavia, ao levar em conta os diferentes padrões de vida nos países, a paridade do poder de compra (PPP), a economia chinesa é a maior do mundo desde 2014. Em termos militares, a China desde2007já se consolidou como o segundo país que mais gasta em defesa, superando potências tradicionais como França e Reino Unido em termos de gastos militares (SIPRI, 2019). Logo, a ascensão chinesa vem provocando transformações na distribuição de poder no sistema internacional e, do ponto de vista econômico, recentralizou parte da economia mundial em seu eixo gravitacional, impactando, inclusive, na dinamicidade econômica de países do Sudeste Asiático na década de 1990 e no século XXI (NOGUEIRA; HENDLER, 2016).

\footnotetext{
4 Nesse caso, na literatura apresenta-se debates que os EUA continuam superiores em relação à China no que diz respeito ao seu desenvolvimento militar (CHRISTENSEN, 2015; BROOKS; WOHLFORTH, 2016). Relatórios da Rand Corporation também apresentam que apesar da modernização chinesa, suas forças militares ainda não se equiparam às forças norte-americanas (HEGINBOTHAM, 2018).
} 
Um relatório da Rand Corporation de 2018 realizou uma análise de diversos cenários de conflito entre EUA e China com relação à Taiwan e ao Mar do Sul da China (1996, 2003, 2020 e 2017), chegando a conclusão de que, a despeito da superioridade militar norte-americana, desde 2010 a China já pode impor empecilhos para a ação dos EUA em seu entorno regional próximo (HEGINBOTHAM, 2018). As regiões de conflito próximas ao heartland chinês impõem limitações geográficas para a capacidade de ação norte-americana. Assim, tal como o coração precisa bater mais forte para levar o sangue para os vasos capilares ou extremidades, quanto mais longe do “beating heart” dos EUA, mais difícil e custosa é a manutenção do seu poder em zonas geográficas afastadas - questão essa que se assemelha ao que Mearsheimer (2001) chama de "poder parador das águas”.

Cabe mencionar ainda que o governo norte-americano tem percebido a ascensão da China como uma ameaça e isso pode ser observado, para além das Estratégias Nacionais, em documentos do exército. Em setembro de 2009, por exemplo, a Marinha e a Força Aérea dos EUA assinaram um memorando confidencial para desenvolver um novo conceito operacional conjunto, denominado AirSea Battle (ASB). Os defensores do ASB frequentemente enfatizam as habilidades crescentes de adversários em potencial (China, Irã, Coreia do Norte, etc.) para negar/impedir/pressionar as forças dos EUA na sua capacidade de entrar ou operar em territórios marítimos adjacentes a esses países. As estratégias e ações A2/AD são vistas como especialmente cruciais para dissuadir ou combater intervenções de terceiros - por exemplo, esforços por parte dos militares dos EUA para ajudar Taiwan no caso de uma crise através do Estreito, ou Arábia Saudita e vizinhos no caso de ataques a navios no Golfo Pérsico (BITZINGER; RASKA, 2013).

No que tange às variáveis intervenientes (variáveis domésticas) deve-se considerar (i) as percepções de ameaçae oportunidades por parte das lideranças e das elites e (ii) a percepção por parte das lideranças e das elites em relação à capacidade de extração de recursos (a potência do estado em relação à sociedade). Em relação ao primeiro ponto, (i) como mencionado, o contexto tóxico do Oriente Médio e a ascensão de Barack Obama redirecionaram os interesses dos EUA para a Ásia devido ao dinamismo econômico da região e a própria ascensão da China. Nesse caso, houve uma evolução discursiva e prática das percepções das lideranças norte-americanas com relação ao contexto asiático, mesmo que em diversos momentos tenham ocorrido ações duvidosas e incongruências que misturavam discursos cooperativos e competitivos. Inicialmente, mesmo antes da oficialização da estratégia Pivô, tais práticas norteavam-se, principalmente, nas ideias de um redimensionamento construtivo e voltando para questões de direitos humanos, economia, segurança e outros - e em um segundo momento voltado, principalmente, para um menor engajamento e uma maior competição com a China momento, inclusive, que torna mais evidente o aumento de dilemas de segurança na região.

Tal ponto e contraste pode ser observado nos dois documentos National Security Strategy (NSS), publicados em 2010 e 2015 durante o governo Obama. O NSS publicado em 2010 apresenta detalhes de como os EUA têm interesse em se aproximar dos países asiáticos por meio de alianças e da estruturação e fortalecimento de mecanismos multilaterais. Também no primeiro documento advoga-se para a continuação de uma relação construtiva, positiva e abrangente com a China e a “convida” para "assumir um papel de liderança responsável juntamente com os Estados Unidos e com a comunidade internacional” (NSS, 2010, p.43, tradução nossa). De fato, diferente do que Bush fez em seu mandato em relação ao Oriente Médio, Obama não estabeleceu diretamente para a Ásia um 'eixo do mal' quando redimensionou seus esforços para a Ásia, o que pode ser observado em seu artigo "Renewing American Leadership” publicado em 2007 que mencionamos anteriormente.

Um exemplo condizente com o argumento sobre a cooperação e a relação construtiva com a China pode ser visto também no discurso de Hillary Clinton em 2012, na Academia de Guerra Naval nos EUA. Na ocasião, a secretária de Estado afirmou que a China não é a URSS e que "nós não estamos à beira de uma nova Guerra Fria na Ásia. Apenas olhe para a expansão do comércio entre as nossas economias, as conexões entre nossos povos, as continuadas consultas entre nossos governos (...) a geopolítica hoje não pode sustentar um jogo de soma-zero” (CLINTON, 2012, traduçãonossa). 
A despeito disso e de ser possível observar esse caráter nos discursos por detrás da política de Obama para a Ásia, um dos efeitos do pivô foi justamente a suspeita (e posterior confirmação) chinesa de que o propósito real da política externa norte-americana fosse a contenção de sua ascensão e expansão de poder, como mencionado (ROSS, 2012; GREEN, 2017). Dessa maneira, as ações do pivô para a Ásia tiveram como efeito o afloramento de percepções de ameaça que foram se retroalimentando, impactando e influenciando para que seintensificassem dilemas de segurança e s eus efeitos espirais. Dessa maneira, a própria atuação norte-americana no contexto asiático gerou instabilidade na região e aflorou, inclusive, as disputas e os tensionamentos entre os países, o que afetou as percepções e imagens das próprias lideranças do Leste Asiático. No caso da China, uma percepção confrontacionista da política dos EUA. No caso de outros países - como Japão, Vietnã e Filipinas -, percepções de um EUA que não teria capacidade de atuar ativamente no Leste Asiático diante de seus constrangimentos internos (OLIVEIRA, 2019).

O NSS de 2015, por sua vez, nos apresenta um cenário e discursos diferenciados a respeito da China quando comparado ao de 2010, muito provavelmente como consequência do aumento da insegurança na região do Leste Asiático, da contínua ascensão chinesa e da maior assertividade chinesa nos teatros marítimos do Sudeste e Nordeste Asiático a partir de 2009 e 2012-2013, respectivamente. Nesse sentido, também aumentaram dilemas de segurançana região devido à transformação de políticas de segurança no Japão, ao fortalecimento de cooperação militar dos EUA com países como Filipinas e Vietnã no Sudeste Asiático e ao aumento da assertividade marítima chinesa (SALTZMAN, 2015; OLIVEIRA; FERNANDES, 2019). No NSS de 2015 é possível observar algumas mudanças a respeito da China: apesar da cooperação e da busca pelo fortalecimento de uma relação construtiva ainda persistir, são evidentes as preocupações dos EUA com os escalonamentos de tensões territoriais na região (NSS, 2015). Não por acaso, diante dos elevados custos operacionais na manutenção de tropas em diversos teatros, os EUA têm buscado reduzir não somente sua presença no Oriente Médio, mas também na Europa. Isso pode ser observado principalmente durante o governo de Donald Trump com suas críticas aos aliados, mas principalmente em relação à OTAN.

No que tange à segunda variável interveniente, (ii) a percepção por parte das lideranças e das elites em relação à capacidade de extração de recursos (a potência do estado em relação à sociedade), nota-se que elas também tiveram efeito considerável na condução da política externa norte-americana para a Ásia do ponto de vista da balança de poder doméstica e em relação à capacidade de mobilização de recursos. Tanto no caso dos interesses nor te-americanos de fortalecimento militar na Ásia, como para a negociação e implementação do TPP, houveram empecilhos domésticos devido às cisões internas dentro do Congresso e das percepções das elites em relação ao apoio da sociedade.

No que tange à defesa, cisões internas entre os republicanos e os democratas aumentaram, assim como cisões dentro de cada um dos partidos (BRANDS, 2017; GREEN, 2017). Devido aos continuados efeitos da crise econômica de 2008 nos EUA, os gastos expressivos em defesa em guerras infinitas no Oriente Médio e diante do problemas do teto da dívida pública norte-americana, segundo Campbell (2016, p.296, tradução nossa), "um número crescente de conservadores fiscais tornou-se cada vez mais cético em relação ao orçamento da defesa, cortando-o e limitando o seu crescimento por meio da Leide Controle Orçamentário (Budget ControlAct) de 2011 e subsequente corte agressivo de gastos”.

Resumidamente, o acúmulo da dívida governamental dos EUA como grande consequência da crise de 2008 fez estourar a capacidade de endividamento do país e com isso, a crise trouxe a necessidade de ajustes na grande estratégia norte-americana. Em 2011, a dívida pública norte-americana alcançou US \$14,3 trilhões, sendo resultado, principalmente, da crise financeira e da atuação do governo nas seguintes agendas: socorro aos bancos e seus programas de incentivo, guerras, cortes de impostos da administração anterior e custos com políticas sociais. A crise do teto da dívida norte americana em $2011 \mathrm{fez}$ com que fosse assinado um projeto de lei no país intitulado Budget Control Act of 2011, onde foi 
estabelecido um aumento da capacidade de endividamento dos EUA. Todavia, a crise continuou o que resultou na lei No Budget, No Pay Act of 2013, que suspendeu a aplicação do teto da dívida temporariamente ${ }^{5}$ (MASTERS, 2013).

Apesar dos cortes no governo Obama e dos problemas orçamentários, o Pentágono conseguiu manter o comprometimento com o Ásia-Pacífico, permanecendo com uma postura militar ativa na região. Contudo, Green (2017) argumenta que o Congresso norte-americano, sobretudo os democratas e o seu poder de veto, impactaram o orçamento do número de navios, tropas, etc., que deveriam ser usados para levar adiante a política mais robusta para a região ${ }^{6}$. Inclusive, a despeito da manutenção de tropas norte-americanas na Ásia, os gastos de defesa e as forças militares dos países foram reduzidos durante a administração de Obama, gerando críticas até a atualidade sobre tal ponto.

Com os contínuos efeitos da crise econômica nos EUA, a política do pivô foi adotada em um momento de enfraquecimento orçamentário, onde qualquer ação mais assertiva e robusta efetivamente para a Ásia fosse intangível. Esse ponto afetou a percepção dos países asiáticos aliados dos EUA com relação ao seu compromisso e a capacidade de mantê-lo. Isso, por sua vez, desencadeou em efeitos que estimularam a militarização e obalanceamento interno de países no Ásia-Pacífico, como exemplo do caso japonês, em relação à China (HUGHES, 2017; OLIVEIRA, 2019). Isso pode s er observado na própria linguagem dos livros de defesa do arquipélago nipônico entre 2011 e 2016 que expressou a necessidade de atenção sobre como os cortes orçamentários dos EUA de 2013 iriam impactar nas estratégias de defesa do país (OLIVEIRA, 2019).

Deve-se ressaltar ainda que os cortes orçamentários se tornaram visíveis na capacidade de Obama manter seu comprometimento com a Ásia quando ele cancelou a sua viagem para a Ásia e a sua presença no APEC (Cooperação Econômica do Ásia-Pacífico) e no EAS em 2013 (BRAND, 2017). Segundo Campbell (2016, p.299, tradução nossa), “as percepções de que os EUA não podem colocar a sua casa em ordem em prioridades básicas traz dúvidas recorrentes sobre a capacidade de permanência do poder dos EUA na Ásia”.

Para o presente artigo, também é importante ressaltarmos o apoio populacional em relação às ações internacionais dos EUA. Em 2012, um estudo conduzido pelo Programa de Consulta Pública em colaboração com o programa de orçamento para relações exteriores e de defesa do Stimson Center e com o Centro de Integridade Nacional Pública de Segurança (Center for Public Integrity National Security), realizou uma pesquisa de opinião sobre se os americanos estavam favoráveis aos cortes de defesa como forma de reduzir o déficit. A maioria dos respondentes afirmou que eram a favor do corte de gastos em defesa, sendo 67\% dos republicanos e 90\% dos democratas pesquisados (PUBLIC CONSULTATION PROGRAM, 2012). Em 2016, uma nova pesquisa foi realizada sobre o questionamento do interesse de Barack Obama em aumentar os gastos em defesa, onde os pesquisados identificados como democratas e independentes votaram majoritariamente a favor de um decréscimo nos gastos, enquanto eleitores republicanos votaram $50 \%$ a favor do decréscimo ou da manutenção dovalor dos gastos e $48 \%$ votaram a favor do aumento.

Para a questão da opinião pública cabe ressaltar também a pesquisa de opinião do Pew Research Center realizada em 2015 direcionada para a política do Ásia Pacífico que apontou que os americanos estavam divididos sobre o comprometimento de recursos de defesa para a Ásia, onde $47 \%$ apoiavam e $43 \%$ se opunham (PEW RESEARCH CENTER, 2015). A pesquisa também apontou que existiam divisões partidárias substanciais sobre o envolvimento americano na

\footnotetext{
${ }^{5}$ Ao passo que os EUA enfrentavam o problema da dívida, o governo começou a estabelecer novos tetos e a cortar gastos em diversas áreas. Isso gerou, e ainda gera, profunda discussão no Congresso diante dos interesses de grande parte dos membros do partido re publicano, no que tange às questões de defesa, apoiarem o aumento dos gastos. Mais recentemente, já durante ogoverno de Donald Trump, em agosto de 2019 foi assinad o o Bipartisan Budget Act of 2019, projeto que eleva os limites de orçamento da lei de 2011 para gastos em defesa e não-defesa, suspende o teto da dívida até 31 de julho de 2021 e estende os cortes em certos programas obrigatórios de 2027 a 2029 (DANIELS; HARRISON, 2019).

${ }^{6}$ Referente a tal questão, um painel do Congresso norte-americano liderado por Bill Perrye Stephen Hadley, em 2010, aconselhou que,diante da crescente importância do Pacífico, o governo norte-americano comprasse e/ou desenvolvesse 350 navios. O Secretário de Defesa naquele ano, Bob Gates, propôs 300 navios. Entretanto, o Congresso cortou os gastos em defesa, o que possibilitou a capacidade de desenvolver e/ou comprar apenas 280 navios. No mesmo ano, Leo Panetta, sucessor de Bob Gates, escreveu, para as lideranças norte-americanas envolvidas em questões militares, que os cortes poderiam fazer com que a marinha norte-americana diminuísse para o seu menor tamanho desde 1915 (GREEN, 2017, p. 522). Nesse mesmo sentido, em 2014 e 2015, o Departamento de Defesa decidiu limitar o número de navios litorâneos de combate a serem produzidos, embarcações estas que eram consideradas importantes armas para contra-atacar as estratégias chinesas $\mathrm{A} 2 / \mathrm{AD}$.
} 
Ásia. Os republicanos são menos favoráveis do que os democratas e os independentes de um possível acordo comercial (TPP), mas mais favoráveis aos compromissos militares americanos na região.

No que tange a defesa, as pesquisas são importantes para apresentar como os entrevistados estavam majoritariamente contrários ao seu aumento de gastos tanto em 2012 como em 2016. Os dados levantados também apontam uma divisão sobre o comprometimento de recursos para a região asiática. Apesar de tal ponto não esboçar, em relação ao pivô, uma completa crítica à ação do governo, demonstra que a capacidade de mobilização de recursos era relativamentelimitada, tanto do ponto de vista populacional como do ponto de vista orçamentário.

No que diz respeito ao TPP, este evoluiu para o interesse de criar um contrapeso ao poder econômico chinês ${ }^{7}$, tanto que, no discurso de 2015 sobre o TPP, Obama afirmou que "quando mais de $95 \%$ de nossos clientes vivem fora de nossas fronteiras, nós não podemos deixar países como a China escrever as regras da economia global. Nós devemos escrever essas regras (...)” (OBAMA, 2015, tradução nossa). Das políticas econômicas e de segurança, podemos afirmar que a primeira sofreu os maiores impactos, visto que a própria estrutura do sistema político democrático e a crise econômica que afetou o país em 2008 ditaram a capacidade de articulação para levar adiante tal estratégia. Sindicatos de trabalhadores e democratas queriam evitar a repetição do Tratado Norte-Americano de Livre Comércio (NAFTA), que gerou a perda de empregos na área manufatureira e déficits comerciais.

Tanto no caso dos gastos em defesa, como no caso do TPP, a opinião pública foi um elemento de provável importância nas discussões políticas entre os partidos e as lideranças devido à balança de poder interno - o que pode ter afetado a formulação, a implementação e a manutenção do pivô. Afinal, ainda no início da implementação da política externa para a Ásia, ao mesmo tempo em que se percebia o poder econômico da China como um dos fatores para o desemprego nos EUA, havia um desgaste dos interesses da sociedade na atuação norte-americana no exterior (BADER, 2013).

As críticas com relação aos gastos orçamentários, os problemas financeiros norte-americanos e a herança no Oriente Médio faziam com que remanejar uma política para a Ásia mais assertiva e robusta fosse mais difícil no contexto da administração de Obama. Ao mesmo tempo em que essa tarefa não era simplória no início do governo de Barack Obama, no final dele se mostrou mais complexa. Afinal, a campanha e a vitória de Donald Trump nas eleições de 2016 esteve apoiada em discursos nacionalistas, isolacionistas, críticos às alianças dos EUA (ideias de share -burden) e ao TPP, por exemplo (SCHWELLER, 2018; SLOAN, 2018; LIND, 2018; OLIVEIRA, 2019).

\section{Considerações Finais}

A administração de Obama tentou reconciliar o interesse de preservar a hegemonia norte -americana em face da ascensão chinesa, de um endividamento nacional alto, de um público desgastado pelas "guerras infinitas" no Oriente Médio e de um apoio doméstico minguante ou dividido em relação às ações dos EUA internacionalmente. Considerando a relevância que a Ásia tem conquistado nos últimos anos na agenda da política externa norte -americana, o presente artigo buscou analisá-la a partir de uma chave realistaneoclássica, considerando as pressões sistêmicas (variável independente) e domésticas (variáveis intervenientes) que afetaram a formulação e a implementação do pivô (variável dependente) durante o governo de Barack Obama (2009-2016).

O artigo observou que apesar da política do pivô ser pressionada pelas transformações na distribuição de poder do Sistema Internacional diante da ascensão da China, deve-se considerar que seus pressupostos, a forma pela qual foi conduzida e a implementação da política foram também influenciadas por fatores domésticos. Tais fatores impactaram tanto a própria política, como a percepção dos países na Ásia a respeito dela e do comprometimento norte -americano com

7 Em 2015, Obama afirmou que "quando mais de 95\% de nossos clientes vivem fora de nossas fronteiras, nós não podemos deixar países como a China escrever as regras da economia global. Nós devemos escrever essas regras (...)” (OBAMA, 2015, tradução nossa). 
o tabuleiro asiático. Inclusive, como apresentado, a política intensificou dilemas de segurança na região durante a administração de Obama, por meio de percepções negativas da China em relação à política e de parceiros norte -americanos que duvidaram dela. Não por acaso, o próprio pivô, discursivamente, nasceu como uma política cooperativa e abrangente em relação à China e à Ásia como um todo. Todavia, com o decorrer de seu desenvolvimento, a política foi compreendida como confrontacionista pela China e, ao mesmo tempo, diante dos problemas domésticos nos EUA, dúvidas emergiram na Ásia sobre a concretização da política. Nesse sentido, para além de uma maior assertividade marítima chinesa nos teatros de segurança do Nordeste e do Sudeste Asiático, países como Japão e Vietnã, por exemplo, estimularam seu recrudescimento militar por meio de um balanceamento interno e externo.

Do ponto de vista doméstico, um dos principais resultados observados no artigo é que a política da Ásia Pivô sofreu com a capacidade de mobilização de recursos que impactou em sua assertividade e robustez. A população norteamericana estava dividida com relação à política, contrária aos gastos de defesa dos EUA no mundo e alguns grupos se mostraram críticos ao TPP. Nesse sentido, o artigo demonstrou como (i) as percepções de ameaça e oportunidades por parte das lideranças e das elites e (ii) a percepção por parte das lideranças e das elites em relaçãoà capacidade de extração de recursos, afetaram a condução da política do pivô para a Ásia. De fato, apesar dos cortes orçamentários e das tensões internas, a política do pivô manteve seu direcionamento do ponto de vista da segurança para a Ásia, sendo o comprometimento com a segurança de seus aliados muito mais crítico e frágil na Europa do que no Ásia -Pacífico.

A política do pivô continua produzindo efeitos na região mesmo após o fim do governo de Barack Obama (2009 2016). Afinal, a política externa do presidente seguinte, Donald Trump (2017-2020), continuou direcionando esforços dos EUA para a região, apesar dos seus constantes blefes. Aind a precisam ser realizados estudos sobre a condução da política externa dos EUA durante o governo de Donald Trump, e sua estratégia de Free and Open Indo-Pacific, para compreender em que medida variáveis domésticas serviram como filtros para as ações dos EUA no Leste Asiático em um segundo momento. Também são necessárias análises de como a geopolítica do Leste Asiático tem se transformado no âmbito das alianças e desavenças entre os países da região durante e após o governo Trump.

Para isso é essencial considerar a evolução da política externa norte-americana para a Ásia e os desdobramentos dos dilemas de segurança na região, sobretudo quando tratamos sobre o ano de 2020, quando ocorrem: i) novas tensões entre China e Japão pelas ilhas Senkaku/Diaoyu,ii) crescentes trocas de acusações entre Donald Trumpe o governo chinês, iii) reavivamento de conflitos fronteiriços entre China e Índia, iv) escalonamento de tensões no Mar do Sul da China, principalmente, entre Vietnã e China e v) aproximação dos EUA de Donald Trump com Taiwan, com a assinatura do Taipei $A c t^{8}$ e outros. Todas essas questões em um cenário de pandemia.

A política do Pivô é um elemento essencial para compreendermos o desenvolvimento da política externa dos EUA para a Ásia e deve-se considerar que os dilemas de segurança na região foram e continuam sendo impactados pela forma como a política de Obama foi conduzida. Ao passo que os efeitos ainda podem ser observados, o artigo demonstrou que para além de uma análise puramente em nível sistêmico, compreender as dinâmicas de balança de poder doméstico, nos permitem melhor entender o comportamento dos Estados e as suas consequências para a balança de poder no sistema internacional.

\section{Referências}

BADER, Jeffrey. Obama and China's Rise: An Insider's Account of America's Asia Strategy. Washington: Brookings Institution Press, 2013.

\footnotetext{
8 O Taipei Act fortalece o compromisso dos EUA com a proteção da posição internacional de Taiwan. Aprovada anteriormente por ambas as casas do Congresso com consentimento unânime, a lei é uma resposta à China. Em resumo, a lei incentiva o apoio ao reconhecimento diplomático de Taiwan, o fortalecimento de laços não oficiais com a ilha e o apoio na participação de Taiwan em organiz ações internacionais (Kuo,2020).
} 
BANCO MUNDIAL.World Bank database, 2020.Disponível em: https://data.worldbank.org/ Acesso em 10 de janeiro de 2020.

BITZINGER, Richard A.; RASKA, Michael. RSIS Policy Brief: The AirSea Battle Debate and the Future of Conflict in East Asia. S. Rajaratram School of International Studies, Graduate School of Nanyang Technological University, 2013. Disponível em: https://www.files.ethz.ch/isn/160037/RSIS_Air\%20Sea\%20Battle_190213\%20v1_Print.pdf Acesso em 10 de setembro de 2020.

BRANDS, Hal; FEAVER, Peter. Stress-Testing American Grand Strategy. Survival, v. 58, n. 6, p. 93-120, 2016.

BRANDS, Hal. Barack Obama and the Dilemmas of American Grand Strategy. The Washington Quarterly, v. 39, n. 4, p. $101-125,2017$. BROOKS, Stephen; WOHLFORTH, William. The Rise and Fall of the Great Powers in the Twenty-First Century. China's Rise and the Fate of America's Global Position. International Security, v. 40,n. 3, p. 7-53 (online), 2016.

CAMPBELL, Kurt. The Pivot. The Future of American Statecraft in Asia. New York: Twelve Hachette Book Group. First Edition, 2016.

CHRISTENSEN, Thomas. Useful Adversaries: Grand Strategy, Domestic Mobilization, and Sino-American Conflict, 1947-1958. Princeton, NJ: Princeton University Press, 1996.

CHRISTENSEN, Thomas. The China Challenge. Shaping the Choices of a Rising Power. W. W. Norton \& Company, Inc, 2015.

CLINTON, Hilary. America's Pacific Century. Foreign Affairs, 2011. Disponível em: https://foreignpolicy.com/2011/10/11/americaspacific-century/ Acesso em 17 de outubro de 2018.

CLINTON, Hilary. Clinton: 'a strong America is welcoming new powers into an international system'. Atlantic Council, 2012. Disponível em: https://www.atlanticcouncil.org/blogs/natosource/clinton-a-strong-america-is-welcoming-new-powers-into-aninternational-system Acesso em 10 de agosto de 2018.

CORDESMAN, Anthony H.; HESS, Ashley. The Evolving Military Balance in the Korean Peninsula and Northeast Asia. Center for Strategic and International Studies, 2013.

DANIELS, Samus; HARRISON, Todd. What Does the Bipartisan Budget Act of 2019 Mean for Defense? CSIS, 2019. Disponível em https://www.csis.org/analysis/what-does-bipartisan-budget-act-2019-mean-defense Acesso em 10 de junho de 2020.

ECONOMY, Elizabeth;SEGAL, Adam. The G-2 Mirage: Why the United States and China Are Not Ready to Upgrade Ties. Foreign Affairs, 2009. Disponível em: https://www.foreignaffairs.com/articles/east-asia/2009-05-01/g-2-mirage Acesso em 10 de setembro de 2020 .

FORD, John. The Pivot to Asia Was Obama's Biggest Mistake. The Diplomat, 2017. Disponível em: https://thediplomat.com/2017/01/the-pivot-to-asia-was-obamas-biggest-mistake/Acesso em 12 de outubro de 2018.

GREEN, Michael J. By More than Providence: Grand Strategy and American Power in the Asia - Pacific Since 1783, NY: Columbia University Press, 2017.

GREEN, Michael J. et al. Power and Order in Asia. A Survey of Regional Expectations. CSIS Report. ROWMAN \& LITTLEFIELD, 2014.

HAROLD, Scott W. Is the Pivot Doomed? The Resilience of America's Strategic 'Rebalance'. The Washington Quarterly, p.85-99,2015.

HEGINBOTHAM, Eric. The China-US Military Scorecard: forces, geography, and the evolving balance of power, 1996-2017. California, Santa Mônica: Rand Corporation, 2018.

HUGHES, Christopher. Japan's Grand Strategic Shift. From the Yoshida Doctrine to an Abe Doctrine? In: TELLIS, Ashley et al. Power, ideas, and military strategy in the Asia-Pacific. p.73-105. Strategic Asia 2017-18, , 2017.

KOLMAS, Michal; KOLMASOVA, Sarka. A 'pivot' that never existed:America's Asian strategy under Obama and Trump. Cambridge Review of International Affairs, v. 32, n. 1, 2019.

KUO, Mercy. Trump and the TAIPEI Act. The Diplomat, 2020. Disponível em: https://thediplomat.com/2020/04/trump-and-thetaipei-act/. Acesso em 10 de junho de 2020.

LIND,Jennifer. The Art of the Bluff: The US-Japan Alliance Under the Trump Administration:JERVIS, Robert. Chaos in the Liberal Order: The Trump Presidency and International Politics in the Twenty-First Century, 1rst ed. Robert Jervis et al. New York, NY: Columbia University, 2018.

MASTERS, Jonathan. U.S. Debt Ceiling: Costs and Consequences. Council of Foreign Relations, 2019. Disponível em https://www.cfr.org/backgrounder/us-debt-ceiling-costs-and-consequences Acesso em 10 de junho de 2020. 
NSS. National Security Strategy. The White House, Washington, 2010. Disponível em: http://nssarchive.us/NSSR/2010.pdf Acesso em 14 de abril de 2017.

NSS. National Security Strategy. The White House, Washington, 2015. Disponível em: http://nssarchive.us/wpcontent/uploads/2015/02/2015.pdf Acesso em 15 de abril de 2017.

OBAMA, Barack. Renewing American Leadership. Foreign Affairs, 2007. Disponível em:

https://www.foreignaffairs.com/articles/2007-07-01/renewing-american-leadership Acesso em 10 de janeiro de 2017.

OBAMA, Barack. Remarks By President Obama to the Australian Parliament. The White House, 2011. Disponível em:

https://obamawhitehouse.archives.gov/the-press-office/2011/11/17/remarks-president-obama-australian-parliament Acesso em 18 de janeiro de 2017.

NOGUEIRA, Isabela; HENDLER, Bruno. O Sudeste Asiático entre Estados Unidos e China: “arquipélago de economias de mercado” ou palco da competição interestatal capitalista?. Carta Internacional, v.11, n.3, p. 199-222,2016.

OLIVEIRA, Alana. Entre o Sol, a Águia e o Dragão: dinâmicas de poder e segurança entre Japão, EUA e China no Leste Asiático e o estudo de caso das ilhas Senkaku/Diaoyu no século XXI.PhD Thesis, UFRJ, 2019.

OLIVEIRA, Alana C. G; FERNANDES, Felipe G. C. O Raiar do Sol no Sudeste Asiático: A Projeção Japonesa no Mar do Sul da China e Seus Interesses Estratégicos. Revista da Escola de Guerra Naval, v. 25, n. 2, 2019, p. 449-491.

PECEQUILO, Cristina S. A política externa dos Estados Unidos. Rio Grande do Sul: UFRGS Editora, 2003.

PECEQUILO, Cristina S. As Grandes Estratégias dos Estados Unidos (1989/2010). Meridiano 47, 2010. Disponível em: http://www.ibri-rbpi.org/?p=2575 Acesso em 10 de janeiro de 2018.

PEW RESEARCH CENTER. Global Publics Back U.S. on Fighting ISIS, but Are Critical of Post-9/11 Torture. Pew Research Center, 2015. Disponível em: https://www.pewresearch.org/global/2015/06/23/global-publics-back-u-s-on-fighting-isis-but-are-critical-of-post911-torture/ Acesso em 10 de agosto de 2019.

PUBLIC CONSUltATION PROGRAM. Majority of Americans are Willing to Make Defense Cuts, New Survey Finds. Public Consultation.org, 2012. Disponível em: https://www.publicconsultation.org/federal-budget/majority-of-americans-are-willing-tomake-defense-cuts-new-survey-finds/Acesso em 10 de janeiro de 2019.

PUBLIC CONSULTATION PROGRAM. Americans Not Sold on Defense Increase. Public Consultation.org, 2016. Disponível em: https://www.publicconsultation.org/defense-budget/americans-not-sold-on-defense-increase/Acesso em 19 de janeiro de 2019.

REUTERS. Senior Chinese diplomat says China, U.S. must avoid Cold War mentality. Reuters, 2018. Disponível em: https://www.reuters.com/article/us-usa-trade-china/senior-chinese-diplomat-says-china-u-s-must-avoid-cold-war-mentalityidUSKCN1M607M Acesso em 5 de abril de 2019.

RIPSMAN, Norrin M.; TALIAFERRO, Jeffrey W.; LOBELL, Steven E. Neoclassical Realist Theory of International Politics. Oxford: Oxford University Press.1st Edition, 2016.

ROSE, Gideon. Neoclassical Realism and Theories of Foreign Policy. World Politics, v. 51, n. 1, p.145-177,1998.

ROSS, Robert. The Problem with the Pivot. Foreign Affairs, v. 91, n. 6, p. 70 - 82, 2012.

SCHWELLER, Randall L. Deadly Imbalances: Tripolarity and Hitler's Strategy of World Conquest. NY: Columbia University Press, 1998.

SCHWELLER, Randall L. Opposite but Compatible Nationalisms: A Neoclassical Realist Approach to the Future of US-China Relations. The Chinese Journal of International Politics, v. 11, n. 1, p. 23-48, 2018.

SLOAN, Stanley R. Donald Trump and NATO: Historic Alliance Meets A-historic President. In: JERVIS, Robert. Chaos in the Liberal Order: the Trump Presidency and International Politics in the 21st Century. New York, NY: Columbia University Press, 2018.

US-CHINA JOINT STATEMENT. U.S.-China Joint Statement. The White House, 2009. Disponível em:

https://obamawhitehouse.archives.gov/realitycheck/the-press-office/us-china-joint-statement Acesso em 14 de janeiro de 2018.

WALTZ, Kenneth N. The New World Order. Millennium. Journal of International Studies, v. 22, n. 2, p.187-195,1993.

WALTZ, Kenneth N. Structural Realism after the Cold War. International Security, v. 25, n. 1, p. 5-41, 2000.

WALTZ, Kenneth N. Theory of International Politics. Reading, MA: Addison-Wesley,1979. 
WOHLFORTH, Williams C. The Stability of a Unipolar World. International Security, v. 24, n. 1, p. 5-41, 1999.

ZAKARIA, Fareed. From Wealth to Power: The Unusual Origins of America's World Role, Princeton: Princeton University Press, 1998

ZHAO, Suisheng. China's Power from a Chinese Perspective (I): A Developing Country versus a Great Power. In: CHUNG,Jae -ho. Assessing China's Power. p.251-270, The Asan Institute, UK: Palgrave Macmillian, 2015.

Funções de colaboração exercidas 